\title{
基于锂盐的新型锂电池电解质研究进展
}

\author{
马国强 ${ }^{1,2}$, 蒋志敏 ${ }^{2}$, 陈慧闯 ${ }^{2}$, 王 莉 ${ }^{1}$, 董经博 ${ }^{2}$,

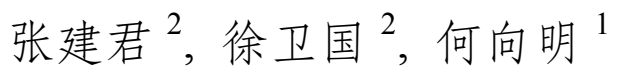

(1. 清华大学核能与新能源技术研究院, 北京市精细陶瓷实验室, 北京 $100864 ; 2$. 浙江省化工研究院有限公司, 杭州 310023)

摘 要: 随着新能源汽车、可携带式电源和储能等领域的快速发展, 人们对锂电池性能提出了更高的要求, 高性能 锂离子电池的重要性日益突出。电解质是锂离子电池的重要组成部分, 对于电池的输出电压、倍率性能、适用温度 范围、循环性能和安全性能等有着重要的影响。而锂盐作为液体电解质(电解液)的关键组分, 是决定电解液性能的 重要因素。电解液中不同种类的锂盐及其在溶液中不同的溶剂化状态, 会对电极/电解液界面的成膜性能和锂离子 的迁移行为等产生重要影响, 进而显著影响电解液的电化学性能。本文介绍了近年来新型电解质锂盐的性质特点和 在不同种类电池中的应用。同时，单一的锂盐不能完全满足锂电池对电解液的要求，因而人们尝试采用复合锂盐使 功能更完善, 催生了多盐体系电解液。多盐体系电解液在拓宽电池工作温度、抑制金属离子溶出和提高倍率性能等 方面表现出明显优势。同时, 借助于浓度的提升改变锂离子的溶剂化结构, 研究人员提出了高浓度电解液。高浓度 电解液在防止石墨剥离、拓宽电解液电化学窗口、抑制铝箔腐蚀和提高金属锂沉积/溶出性能等方面具有明显优势。 并且, 本文重点讨论了这两种电解液对电池性能提升的机理。最后, 对锂盐基电解液尤其是这两类新型电解液的发 展趋势和应用前景进行了展望。

关 键 词: 电解质; 锂盐; 多盐电解液; 高浓度电解液; 综述

中图分类号: TQ174 文献标识码: A

\section{Research Process on Novel Electrolyte of Lithium-ion Battery Based on Lithium Salts}

\author{
MA Guo-Qiang ${ }^{1,2}$, JIANG Zhi-Min², CHEN Hui-Chuang ${ }^{2}$, WANG Li ${ }^{1}$, DONG Jing-Bo ${ }^{2}$, \\ ZHANG Jian-Jun ${ }^{2}$, XU Wei-Guo ${ }^{2}$, HE Xiang-Ming ${ }^{1}$
}

(1. Beijing Key Lab of Fine Ceramics, Institute of Nuclear \& New Energy Technology, Tsinghua University, Beijing 100864, China; 2. Zhejiang Chemical Industry Research Institute Co. Ltd., Hangzhou 310023, China)

\begin{abstract}
With the development of electric vehicles, portable applications and energy storage systems, high-performance lithium-ion batteries are urgently demanded, and the corresponding research becomes much more important. Electrolyte is one of the indispensable components for lithium-ion battery, resulting in a significant impact on the rate performance, temperature range, cycling performance, safety issue and so on. Lithium salt as the key component, is an important factor dominating the performance of the electrolyte. Various lithium salts and their solvation
\end{abstract}

收稿日期: 2017-11-06; 收到修改稿日期：2018-01-16

基金项目: 国家自然科学基金重大项目(U1564205); 中国科技部项目(2016YFE0102200); 中国博士后科学基金(2016M590550); 浙 江省科技厅项目(2016F50051)

National Natural Science Foundation of China (U1564205); Ministry of Science and Technology of China (2016YFE0102200);

China Postdoctoral Science Foundation (2016M590550); Zhejiang Province Research Institutes Special Fund (2016F50051)

作者简介: 马国强(1986-), 男，博士. E-mail: maguoqiang@sinochem.com

通讯作者：何向明，教授. E-mail: hexm@tsinghua.edu.cn 
structures in the electrolyte evidently affect the quality of SEI layer derived from electrolytes and lithium ion migration behavior, leading to completely different electrochemical properties. The characteristics of different novel lithium salts are introduced in detail. Furthermore, the fact that a single lithium salt can't meet all the required performance propels to design the high performance electrolyte with multi-salts. This electrolyte shows a series of advantages in expanding the working temperature range, suppressing the metal ion dissolution and improving the rate performance. Simultaneously, based on tuning the solvation structure of $\mathrm{Li}^{+}$by increasing the concentration, a novel concentrated electrolyte is introduced, displaying the advantages such as the suppressed graphite peeling, the expanded electrochemical window, the suppressed Al corrosion, the improved metallic lithium plating/stripping and so on. Furthermore, detail discussion focuses on the mechanisms for the enhanced performance of the two excellent electrolytes. Finally, development tendency and application prospect of lithium-salt based electrolytes, especially these two novel electrolytes are discussed.

Key words: electrolyte; lithium salts; multi-salts electrolyte; concentrated electrolyte; review

锂离子电池具有能量密度大、工作电压高、无 记忆功能和使用寿命长等特点, 是目前应用最广的 可充式电池 ${ }^{[1]}$ 。如今, 锂离子电池已经在手机、笔记 本电脑等便携式电子设备中占据主导地位。同时, 基于环保和国家战略考虑, 我国大力鼓励电动汽车 用动力电池的快速发展。另外, 风能、太阳能和生 物质能等新型能源的利用离不开储能技术的进步, 也为锂离子电池的发展提供了广阔市场。但是, 随 着技术的进步和社会的发展, 人们对锂离子电池的 能量密度、倍率性能、适用温度、循环寿命和安全 性等都提出了更高的要求, 这些都有赖于正极、负 极、电解液和隔膜锂电池四大关键材料的进步。

电解质是锂离子电池中锂离子在正负极之间传 输的媒介 ${ }^{[2]}$, 可分为固体电解质和电解液, 固体电 解质尚处于研发阶段, 而电解液广泛应用于当前商 用锂电池, 也是本文介绍的重点。电解液作为锂电 池的关键材料, 直接影响电池的倍率、容量、循环 寿命、适用温度和安全等性能 ${ }^{[3-4]}$ 。电解液一般由锂 盐、溶剂和添加剂组成。锂盐是电解液中锂离子的 提供者, 目前, 常见的锂盐有 $\mathrm{LiPF}_{6}$ (六氟磷酸锂)、 $\mathrm{LiAsF}_{6}$ (六氟砷酸锂)、 $\mathrm{LiClO}_{4}$ (高氯酸锂) 等, 但是 $\mathrm{LiAsF}_{6}$ 具有毒性且价格昂贵; $\mathrm{LiClO}_{4}$ 具有较大的安 全风险, 因而这两种锂盐罕有使用 ${ }^{[5]}$ 。 $\mathrm{LiPF}_{6}$ 以其极 高的离子电导率, 优异的氧化稳定性和较低的环境 污染性, 是应用最广泛的电解质锂盐。但 $\mathrm{LiPF}_{6}$ 也存

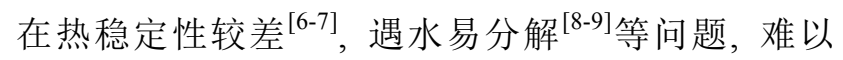
满足高性能锂离子电池的需求。因此 $\operatorname{LiFSI}$ (双氟磺 酰亚胺锂)、LiTFSI(双三氟甲基磺酰亚胺锂)、 $\mathrm{LiBF}_{4}$ (四氟喼酸锂)、 $\mathrm{LiBOB}$ (二草酸喼酸锂)、 $\mathrm{LiDFOB}$ (草酸二氟硼酸锂)、 $\mathrm{LiPF}_{2} \mathrm{O}_{2}$ (二氟磷酸锂) 和 $\operatorname{LiDTI}(4,5$-二氧基-2-三氟甲基咪唑锂)等新型锂 盐的开发逐渐受到了科研人员的重视。
锂盐是电解液的重要组成部分, 其阴离子是决 定电解液物理和化学性质的主要因素。随着人们对 电池高电压和快速充放电性能提出了更高要求, 以 及对极端性能锂电池的需求日益迫切, 锂盐成为攻 克锂离子电池性能提升难题的突破口之一。本文综 述了新型锂盐的研究进展, 对其优缺点进行了评述, 重点介绍了多盐体系电解液和高浓度锂盐电解液两 种新型电解液, 分析了其作用原理, 并对其应用前 景进行了展望。

\section{1 锂盐}

\section{1 锂盐所应具备的性质和作用}

理想电解质锂盐需具备的一系列特性:

(1)低解离能和较高的溶解度

锂盐在溶液中溶解伴随着锂盐中阴阳离子的解 离, 形成溶剂化的溶液结构。低解离能保证锂盐溶 解后形成的电解液具有较高的电导率, 进而实现电 池的高倍率 ${ }^{[10]}$ 。同时, 锂盐需要在适当溶剂中具有 较高的溶解度, 以保证电解液中具有足够的锂离子 进行传输。

\section{(2)较好的稳定性}

锂盐应具有较好的热稳定性、化学稳定性和电 化学稳定性。当电池在高电压、高温下工作时, 锂 盐不会与其他组分发生反应。且要求对电解液中的 痕量水保持稳定 ${ }^{[11]}$ 。

(3)良好的 SEI 成膜性能

电极表面在首圈循环后会形成一层固态电解质 膜(SEI 膜), 这层针化膜能够允许 $\mathrm{Li}^{+}$而阻挡电子通 过, 并阻止电解液的连续消耗, 对电池循环稳定性 具有重要意义 ${ }^{[12]}$ 。良好的锂盐需要对电极形成稳定 的 SEI 膜, 以保证后续循环过程中电解液不会被持 
续消耗。

(4)对 $\mathrm{Al}$ 集流体具有良好的针化作用

目前商业化锂离子电池几乎都使用 $\mathrm{Al}$ 箔作为 正极集流体, 该锂盐电解液必须在 $\mathrm{Al}$ 箔表面形成有 效的针化膜, 防止高电压下腐蚀 $\mathrm{Al}$ 䇴 ${ }^{[13]}$ 。

(5)成本低廉, 无毒无公害

能够同时满足以上要求的锂盐非常少。由于锂 离子半径小, 因而许多简单的盐(如 $\mathrm{LiF} 、 \mathrm{LiCl} 、 \mathrm{Li}_{2} \mathrm{O}$ 、 $\mathrm{Li}_{2} \mathrm{~S}$ 等) 因溶解度太低而不能成为锂电池电解液锂 盐。尽管这些阴离子被软 Lewis 碱替代(如 LiBr、LiI 等)后溶解度有所提升，但却带来不耐氧化的问题。 采用 Lewis 酸剂稳定简单阴离子核心, 组成复杂的 阴离子的锂盐能满足溶解度的要求, 比如六氟磷酸 锂的阴离子 $\mathrm{PF}_{6}{ }^{-}$可以看作是 Lewis 酸核心 $\mathrm{PF}_{5}$ 和 $\mathrm{F}$ 组成的复杂阴离子。这种阴离子被称为超酸阴离子, 其中的负电荷被具有强吸电子能力的 Lewis 酸基团 $\mathrm{F}^{-}$所吸引, 这种阴离子的锂盐在溶剂中具有较高的 溶解度。锂盐在溶液中溶解后形成的电解液中离子 的迁移分以下两个过程: 锂盐的溶剂化/解离和电 解液中锂离子的流动性。下面展示不同锂盐的离子 流动性和解离常数, 从结果可见, 锂盐的流动性和 解离常数基本是一对矛盾体, 因此, 锂盐的选择通 常是折中的结果。

离子流动性: $\mathrm{LiBF}_{4}>\mathrm{LiClO}_{4}>\mathrm{LiPF}_{6}>\mathrm{LiAsF}_{6}$ 。

解离常数: $\mathrm{LiBF}_{4}<\mathrm{LiClO}_{4}<\mathrm{LiPF}_{6}<\mathrm{LiAsF}_{6}$ 。

另外, 电解液性质还会受到溶剂的种类、锂盐 浓度和添加剂等因素的影响。

\section{2 不同种类的锂盐介绍}

\subsection{1 $\mathrm{LiPF}_{6}$}

$\mathrm{LiPF}_{6}$ 是应用最广的锂盐。与其他锂盐相比, $\mathrm{LiPF}_{6}$ 的单一性质并不是最突出, 但在以碳酸酯混 合物为溶剂的锂电池电解液中, $\mathrm{LiPF}_{6}$ 具有相对最优 的综合性能。 $\mathrm{LiPF}_{6}$ 有以下突出优点: (1)在非水溶剂 中具有合适的溶解度和较高的离子电导率; (2)能在 $\mathrm{Al}$ 箔集流体表面形成一层稳定的针化膜; (3)能协同 碳酸酯溶剂在石墨电极表面生成一层稳定的 SEI 膜。但是, $\mathrm{LiPF}_{6}$ 的热稳定性较差 ${ }^{[14]}$, 易发生分解反应:

$$
\mathrm{LiPF}_{6} \rightleftharpoons \mathrm{LiF}+\mathrm{PF}_{5}
$$

同时, $\mathrm{LiPF}_{6}$ 中的 $\mathrm{P}-\mathrm{F}$ 键对水分非常敏感，当微量水 分存在时，就会发生下列反应:

$$
\begin{gathered}
\mathrm{LiPF}_{6}+\mathrm{H}_{2} \mathrm{O} \rightleftharpoons \mathrm{LiF}+\mathrm{POF}_{3}+2 \mathrm{HF} \\
\mathrm{PF}_{5}+\mathrm{H}_{2} \mathrm{O} \rightleftharpoons \mathrm{POF}_{3}+2 \mathrm{HF}
\end{gathered}
$$

$\mathrm{LiPF}_{6}$ 在电解液中的副反应产物 $\mathrm{HF}$ 和 $\mathrm{POF}_{3}$, 会破坏 电极表面 SEI 膜, 还会溶解正极活性组分, 导致循 环过程中容量严重衰减 ${ }^{[15]}$ 。因此, 为满足锂离子电
池更高的性能要求，迫切需要开发一种水解稳定性 好、且在高低温下均表现出优异电化学性能的新型 锂盐电解液。

\subsection{2 $\mathrm{LiBF}_{4}$}

$\mathrm{LiBF}_{4}$ 是一种常用锂盐添加剂。与 $\mathrm{LiPF}_{6}$ 相比, $\mathrm{LiBF}_{4}$ 的工作温度区间更宽，高温下稳定性更好， 且低温性能也较优 ${ }^{[16]}$ 。Zhang 等 ${ }^{[17]}$ 使用 $\mathrm{LiBF}_{4}$ 作为 电解液锂盐, 其电池能承受 $50^{\circ} \mathrm{C}$ 的高温, 且低温性 能也得到了改善。此外, $\mathrm{LiBF}_{4}$ 还能增强电解液对电 极的成膜能力, 抑制 $\mathrm{Al}$ 箔腐蚀。但由于 $\mathrm{BF}_{4}{ }^{-}$半径较 小, 不易解离, 导致 $\mathrm{LiBF}_{4}$ 基的电解液离子电导率 较低。因此, $\mathrm{LiBF}_{4}$ 单独作为电解质锂盐时有很大局 限性, 常与电导率较高的锂盐配合使用 ${ }^{[18]}$ 。

\subsubsection{LiBOB}

近年来，嗍酸锂配合物作为一种新型电解质锂 盐, 逐渐成为研究热点。 $\mathrm{LiBOB}$ 具有较高的电导率、 较宽的电化学窗口和良好的热稳定性 ${ }^{[19-20]}$, 受到研 究人员广泛关注。其最大优点在于成膜性能 ${ }^{[21]}$, LiBOB 直接参与了 SEI 膜的形成, 即使采用 PC( 碳 酸丙烯酯)作为溶剂也可阻止石墨的剥离 ${ }^{[22]}$, 具有 较好的循环稳定性。同时, $\mathrm{LiBOB}$ 和 $\mathrm{LiPF}_{6}$ 一样对正 极 $\mathrm{Al}$ 䇠集流体具有钝化保护作用。但 $\mathrm{LiBOB}$ 也存 在一些问题, 如溶解度较低, 在部分低介电常数溶 剂中几乎不溶解 ${ }^{[23]}$ 。

\subsubsection{LiDFOB}

从化学结构看, $\mathrm{LiDFOB}$ 是由 $\mathrm{LiBOB}$ 和 $\mathrm{LiBF}_{4}$ 各自的半分子构成，因此综合了 $\mathrm{LiBOB}$ 成膜性好和 $\mathrm{LiBF}_{4}$ 低温性能好的优点。与 LiBOB 相比, LiDFOB 在线性碳酸酯溶剂中具有更高溶解度, 且电解液电 导率也更高 ${ }^{[24]}$ 。研究发现, LiDFOB 高温性能 ${ }^{[25]}$ 和 低温性能 ${ }^{[26]}$ 都好于 $\mathrm{LiPF}_{6}$, 且与电池正极也有很好 相容性，能在 $\mathrm{Al}$ 䇴表面形成一层钝化膜，并抑制电 解液氧化。这些优良性质使其具有替代 $\mathrm{LiPF}_{6}$ 的可 能性, 但目前 LiDFOB 售价较高, 经常以添加剂形 式使用。

\subsubsection{LiTFSI}

LiTFSI 结构中的 $\mathrm{CF}_{3} \mathrm{SO}_{2}$ 基团具有强吸电子作 用 ${ }^{[15]}$, 加剧了负电荷的离域, 降低了离子缔合配对, 使该盐具有较高溶解度。LiTFSI 有较高的电导率, 热分解温度超过 $360^{\circ} \mathrm{C}$, 同时不易水解。但电压高于 $3.7 \mathrm{~V}$ 时会严重腐蚀 $\mathrm{Al}$ 集流体。因此, 研究人员通 常使用合适的添加剂, 或是延长全氟代烷基链长度 等方法改善 LiTFSI 电解液中 $\mathrm{Al}$ 箔的耐腐蚀能力 ${ }^{[27]}$ 。 LiTFSI 对于电压要求不高的电池体系, 比如充电电 压低于 $3 \mathrm{~V}$ 的锂硫电池具有明显的优势。

\subsubsection{LiFSI}

LiFSI 分子中的氟原子具有强吸电子性，能使 $\mathrm{N}$ 
上的负电荷离域, 离子缔合配对作用较弱, $\mathrm{Li}^{+}$容易 解离, 因而电导率较高 ${ }^{[28]}$ 。相比商业化 $\mathrm{LiPF}_{6}, \mathrm{LiFSI}$ 具有电导率高、水敏感度低和热稳定性好等优点。相 比 LiTFSI, LiFSI 对 Al 篞的腐蚀电位更高 $(4.2 \mathrm{~V})$ 。此 外, 还能有效提高低温放电性能, 抑制软包电池胀气。

\subsection{7 $\quad \mathrm{LiPO}_{2} \mathrm{~F}_{2}$}

$\mathrm{LiPO}_{2} \mathrm{~F}_{2}$ 具有较好的低温性能, 同时也能改善 电解液的高温性能。 $\mathrm{LiPO}_{2} \mathrm{~F}_{2}$ 通常作为添加剂使用, 能在负极表面形成一层富含 $\mathrm{Li}_{x} \mathrm{PO}_{y} \mathrm{~F}_{z}$ 和 $\mathrm{LiF}$ 成分的 SEI 膜, 有利于降低电池界面阻抗, 有效提升电池 的循环性能 ${ }^{[29]}$ 。但是, $\mathrm{LiPO}_{2} \mathrm{~F}_{2}$ 也存在溶解度较低的 缺点。

\subsubsection{LiDTI}

LiDTI 的热稳定温度高达 $285^{\circ} \mathrm{C}^{[30]}$, 且具有针 化 $\mathrm{Al}$ 箔和对水稳定的优点。Sabrina 等 ${ }^{[31]}$ 使用 LiDTI 作为电解液锂盐, 对其性能展开研究。相比 $\mathrm{LiPF}_{6}$, LiDTI 有更好的热力学稳定性。该电解液体系可在 $4.5 \mathrm{~V}$ 电压下稳定存在, 能满足商品化正极材料的 充放电需求。

一些锂盐的性质见表 1 。

\section{3 锂盐在电解液中的溶剂化状态和作用}

\subsection{1 锂盐的溶剂化状态}

不同浓度电解液中, 锂盐以不同的锂盐-溶剂 化合物形式存在。锂离子半径小, 具有较高的电荷 密度, 非质子溶剂作为一种路易斯碱, 相比阴离子 (路易斯碱)更容易与阳离子(路易斯酸)络合。因此, 电解液中溶剂分子和阴离子都会与 $\mathrm{Li}^{+}$结合, 形成 $\mathrm{Li}^{+}$-溶剂对, 或者 $\mathrm{Li}^{+}$-阴离子对, 相互之间产生竞 争作用。且该作用受锂盐浓度和温度影响, 会形成 多种形式的锂盐-溶剂化合物, 例如分离离子对形 式(SSIPs, 阴离子不与 $\mathrm{Li}^{+}$直接相连), 接触离子对 形式(CIPs, 阴离子与一个 $\mathrm{Li}^{+}$络合)和聚集体形式 (AGGs，阴离子与两个或以上的 $\mathrm{Li}^{+}$络合 $)^{[42]}$ 。
随着电解液中锂盐浓度升高, 离子间络合作用 增强, 溶剂化状态从 SSIPs 变为 CIPs, 再转变为 AGGs, 同时电解液中自由溶剂分子数不断减少。在 较低浓度 $\left(1 \mathrm{~mol} \cdot \mathrm{L}^{-1}\right.$ 以下 $)$ 电解液溶液中, $\mathrm{Li}^{+}$更易与 溶剂分子结合, 锂盐主要以 SSIPs 形式存在, 且电 解液中存在大量自由溶剂分子。随着锂盐浓度的提 高, 更倾向以 CIPs 和 AGGs 的形式存在。

\subsection{2 锂盐的溶剂化作用}

锂盐的溶剂化作用在电池充放电过程中有直观 的体现(图 1), $\mathrm{Li}^{+}$在电解液中以溶剂化络合物形式 迁移, 如放电过程中, 配位络合物迁移到正极表面, 而电子则由外电路迁移到正极, $\mathrm{Li}^{+}$脱溶剂化进入正 极层状结构完成放电过程。充电过程, 则正好相反。

通常认可的 SEI 膜形成机理如图 2(a)所示, 充 电放电过程中 $\mathrm{Li}^{+}$以单独离子形式迁移, 电荷传输 阻抗 $R_{\mathrm{ct}}$ 指 $\mathrm{Li}^{+}$在石墨层间进行电荷传输得到电子过 程产生的阻抗值。Xu 等 ${ }^{[43]}$ 对模型进行了改进, 如图 2(b) 所示, $R_{\mathrm{ct}}$ 阻抗指 $\mathrm{Li}^{+}$脱溶剂化过程产生的电荷传输 阻抗, $\mathrm{Li}^{+}$与溶剂分子以四配位络合形式进行迁移。 在第一圈充电过程中, 溶剂化的 $\mathrm{Li}^{+}$转移到负极石 墨层表面, 得到电子被还原, 还原产物在石墨层表 面沉积形成 SEI 膜。后续充电过程中, 该 SEI 膜能 阻止 $\mathrm{Li}^{+}$-溶剂化合物在石墨层中的共嵌。

锂盐的选取对电解液性能有十分重要的影响, 而各种锂盐的性能特点也有很大差异, 为提高电解 液性能，可选取两种或者多种锂盐，形成多盐体系 电解液。也可以提高锂盐浓度以改变锂盐溶剂化状 态, 影响 SEI 膜形成和正极界面电化学行为, 从而 提高电池循环稳定性、高温性能和倍率性能。

\section{2 基于锂盐的新型电解液研究进展}

随着高性能锂离子电池的发展, 对于电解液提

表 1 一些锂盐的性质

Table 1 Properties of some lithium salts

\begin{tabular}{|c|c|c|c|c|c|}
\hline $\begin{array}{l}\text { Lithium } \\
\text { salt }\end{array}$ & $\begin{array}{l}\text { Ionic conductivity } \\
(\text { Solvent }) /\left(\mathrm{mS} \cdot \mathrm{cm}^{-1}\right)\end{array}$ & $\begin{array}{l}\text { Oxidation potential(Solvent and } \\
\left.\text { working electrode)/V (vs. } \mathrm{Li} / \mathrm{Li}^{+}\right)\end{array}$ & $\begin{array}{l}\text { Al- } \\
\text { corrosion }\end{array}$ & $\begin{array}{l}\text { Melting } \\
\text { point } /{ }^{\circ} \mathrm{C}\end{array}$ & $\begin{array}{l}\text { Initial decomposition } \\
\text { temperature } /{ }^{\circ} \mathrm{C}\end{array}$ \\
\hline $\mathrm{LiPF}_{6}$ & $10.8\left(\mathrm{EC}: \mathrm{DMC}=1: 1^{\mathrm{b}}\right)^{[32]}$ & $>5.1\left(\mathrm{EC}: \mathrm{DMC}=1: 1^{\mathrm{b}}, \mathrm{Li}_{1-x} \mathrm{Mn}_{2} \mathrm{O}_{4}\right)^{[34]}$ & $\mathrm{N}$ & $200^{[38]}$ & $125^{[40]}$ \\
\hline $\mathrm{LiClO}_{4}$ & $10.1\left(\mathrm{EC}: \mathrm{DMC}=1: 1^{\mathrm{a}}\right)^{[32]}$ & $>5.1\left(\mathrm{EC}: \mathrm{DMC}=1: 1^{\mathrm{b}}, \mathrm{Li}_{1-\chi} \mathrm{Mn}_{2} \mathrm{O}_{4}\right)^{[34]}$ & $\mathrm{N}$ & $236^{[38]}$ & $450^{[41]}$ \\
\hline $\mathrm{LiBF}_{4}$ & $4.9\left(\mathrm{EC}: \mathrm{DMC}=1: 1^{\mathrm{b}}\right)^{[32]}$ & $>5.1\left(\mathrm{EC}: \mathrm{DMC}=1: 1^{\mathrm{b}}, \mathrm{Li}_{1-\chi} \mathrm{Mn}_{2} \mathrm{O}_{4}\right)^{[34]}$ & $\mathrm{N}$ & $293-300^{[38]}$ & $175^{[40]}$ \\
\hline LiTFSI & $9\left(\mathrm{EC}: \mathrm{DMC}=1: 1^{\mathrm{b}}\right)^{[32]}$ & $4.35\left(\mathrm{EC}: \mathrm{DMC}=1: 1^{\mathrm{b}}, \mathrm{Li}_{1-\chi} \mathrm{Mn}_{2} \mathrm{O}_{4}\right)^{[34]}$ & $\mathrm{Y}$ & $234^{[39]}$ & $360^{[14]}$ \\
\hline LiFSI & $9.73\left(\mathrm{EC}: \mathrm{EMC}=3: 7^{\mathrm{a}}\right)^{[33]}$ & $5.6\left(\mathrm{EC}: \mathrm{DMC}=1: 1^{\mathrm{a}}, \mathrm{Pt}\right)^{[35]}$ & $\mathrm{Y}$ & $135^{[33]}$ & $200^{[33]}$ \\
\hline LiBOB & $14.9(\mathrm{DME})^{[32]}$ & $4.6\left(\mathrm{PC}: \mathrm{EC}: \mathrm{DEC}=1: 1: 1^{\mathrm{a}}, \mathrm{Pt}\right)^{[36]}$ & $\mathrm{N}$ & $>300^{[38]}$ & $275^{[40]}$ \\
\hline LiDFOB & $8.58\left(\mathrm{EC}: \mathrm{DMC}=1: 1^{\mathrm{a}}\right)^{[32]}$ & $>6\left(\mathrm{PC}: \mathrm{EC}: \mathrm{EMC}=1: 1: 3^{\mathrm{a}}, \mathrm{Al}\right)^{[37]}$ & $\mathrm{N}$ & $265-271^{[38]}$ & $200^{[40]}$ \\
\hline LiTDI & $6.7\left(\mathrm{EC}: \mathrm{DMC}=1: 1^{\mathrm{b}}\right)^{[32]}$ & $>4.5\left(\mathrm{EC}: \mathrm{DMC} 1: 1^{\mathrm{b}}, \mathrm{Pt}\right)^{[31]}$ & $\mathrm{N}$ & - & $285^{[31]}$ \\
\hline
\end{tabular}

a: By volume; b: By weight; EC: Ethylene carbonate; DMC: Dimethyl carbonate; EMC: Ethyl methyl carbonate 


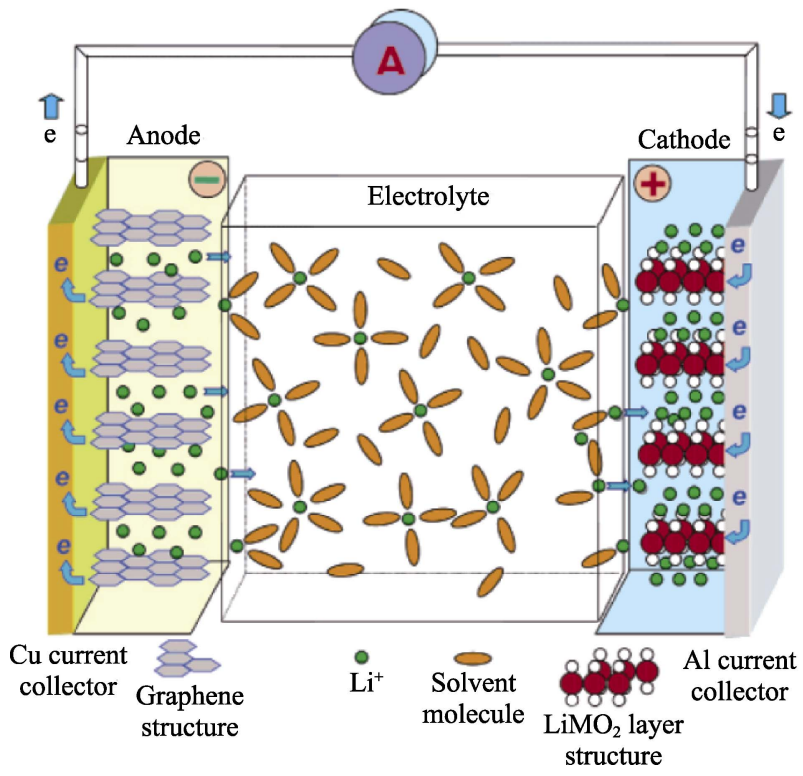

图 1 锂离子电池工作原理图 ${ }^{[16]}$

Fig. 1 The working mechanism of lithium-ion battery ${ }^{[16]}$

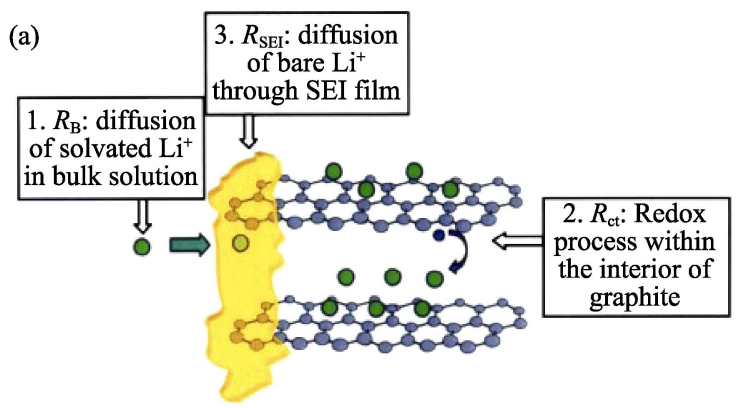

(b)

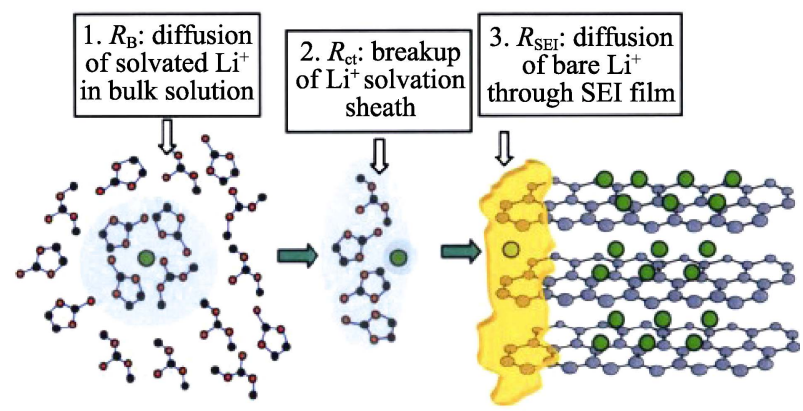

图 $2 \mathrm{Li}^{+}$溶剂化合物从电解液迁移到石墨层间的过程及相 应的阻抗图 ${ }^{[43]}$

Fig. 2 Schematic description of a solvated lithium ion's journey from solution bulk to grapheneinterior, and the impedance components associated with these steps ${ }^{[43]}$

(a) Conventional model; (b) Improved model

出了更高标准的要求, 而传统意义上的电解液已无 法满足这一需求。因此, 研究人员致力于寻找一种 合适的电解液配方, 能够满足新形势下锂离子电池 发展的要求。但电解液研发存在一系列限制条件: 第一，只有特定有机碳酸酯溶剂 $\mathrm{EC}($ 碳酸乙烯酯) 能
够与石墨负极兼容; 第二，需选择合适的锂盐，能 在正极 $\mathrm{Al}$ 䇴集流体表面形成有效针化膜，抑制 $\mathrm{Al}$ 腐蚀; 第三，还要综合考虑电解液的离子电导率、黏 度和锂盐溶解度等因素。

\section{1 多盐体系电解液的研究}

\subsection{1 常规锂离子电池中的应用}

(1)拓宽工作温度区间

Chen 等 ${ }^{[4]}$ 为保证 $\mathrm{LiFePO}_{4}$ 电池高温下的循环稳 定性，使用 LiTFSI 和 LiBOB 混合锂盐。LiBOB 可 以有效抑制 $\mathrm{Al}$ 箔腐蚀。同时, 该多盐体系电解液电 池在 $60^{\circ} \mathrm{C}$ 较高温度下仍具有优异的电化学性能。

Zhang 等 ${ }^{[18]}$ 为提高 $\mathrm{LiFePO}_{4}$ 电池在较宽温度范 围的电化学性能, 分别使用 LiTFSI/LiBOB 和 $\mathrm{LiBF}_{4} / \mathrm{LiBOB}$ 两种混合锂盐电解液。 $65^{\circ} \mathrm{C}$ 下以 $1 C$ 倍率充放电, 使用上述两种混合锂盐电解液电池性 能表现均优于 $\mathrm{LiPF}_{6}$ 基电解液的电池。

王青䂞等 ${ }^{[45]}$ 研究了 LiTFSI/LiDFOB 混合锂盐 电解液用于 $\mathrm{LiFePO}_{4}$ 电池在高温 $60^{\circ} \mathrm{C}$ 下的电化学性 能。当 LiTFSI 与 LiDFOB 摩尔比为 4:6, $1 C$ 倍率进 行充放电时，循环 80 圈后容量保留率达 $99.7 \%$, 而 使用 $\mathrm{LiPF}_{6}$ 基电解液电池容量保留率仅为 $58.6 \%$ 。

(2)抑制金属离子溶出

由于 $\mathrm{LiPF}_{6}$ 基电解液极易与水反应生成 $\mathrm{HF}$, 侵 蚀电池正极材料, 导致金属离子溶出 ${ }^{[46-47]}$, 并在石 墨表面沉积, 对负极表面膜的形成与生长起到催化 作用, 不仅会消耗大量 $\mathrm{Li}^{+}$, 还会造成电池阻抗急剧 增加。以上问题均导致电池容量严重衰减。

宋海申等 ${ }^{[48]}$ 分别以 $\mathrm{LiPF}_{6} 、 \mathrm{LiBOB}$ 和 $\mathrm{LiPF}_{6} / \mathrm{LiBOB}$ 作为电解质, 研究了不同电解液对 $\mathrm{LiFePO}_{4} /$ 石墨动 力电池性能的影响。结果表明, 混合锂盐中的 $\mathrm{LiBOB}$ 能有效抑制正极金属离子溶出，而 $\mathrm{LiPF}_{6}$ 组 分则解决了 $\mathrm{LiBOB}$ 导电性差、表面阻抗较大的固有 缺陷。

(3)快速充放电能力

$\mathrm{Kim}$ 等 ${ }^{[49]}$ 使用 $\mathrm{LiPO}_{2} \mathrm{~F}_{2}$ 和 $\mathrm{VC}$ (碳酸亚乙烯酯) 加入到 $\mathrm{LiPF}_{6}$ 电解液, 提高了石墨/ $\mathrm{Li}$ 半电池的倍率 性能, 如图 3 所示。

\subsection{2锂金属电池中的应用}

$\mathrm{Li}$ 金属具有极高的比容量 $\left(3.86 \mathrm{Ah} \cdot \mathrm{g}^{-1}\right)$ 和极低 的化学电势 $(-3.04 \mathrm{~V}, v s$. NHE), 因此 Li 金属负极比 石墨负极更易获得高的能量密度 ${ }^{[00-51]}$ 。由于突出的 能量密度优势, 包括 Li-S、 $\mathrm{Li}^{-} \mathrm{O}_{2}$ 在内的锂金属电池 近年来受到研究人员的广泛关注 ${ }^{[52]}$ 。但锂金属电池 也存在一系列问题, 如库伦效率低、易形成锂枝晶 等, 影响循环性能和安全性能 ${ }^{[53-54]}$ 。 


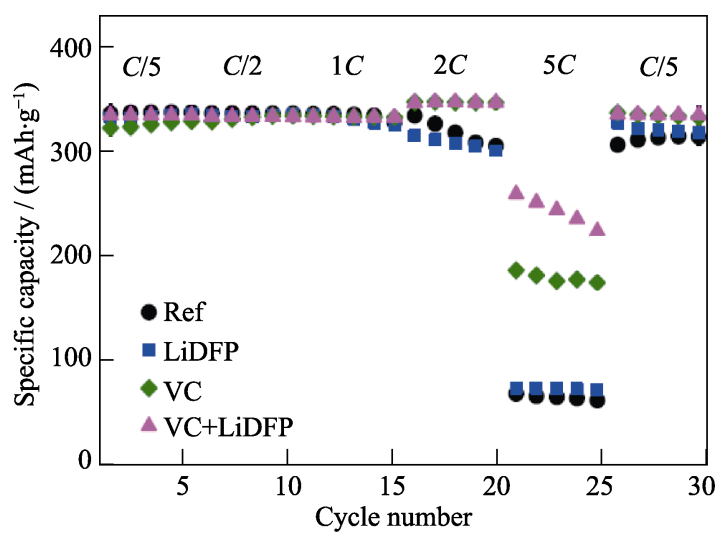

图 3 石墨 $/ \mathrm{Li}$ 半电池在不同倍率下的放电比容量 ${ }^{[49]}$

Fig. 3 Rate capabilities of graphite/Li half cells at various discharge rates $^{[49]}$

Miao 等 ${ }^{[55]}$ 在 $\mathrm{Li} / \mathrm{LiFePO}_{4}$ 电池中使用 $\mathrm{LiFSI} / \mathrm{LiTFSI}$ 多盐体系电解液, 以解决锂金属电池存在的库伦效 率低和锂枝晶形成问题。研究发现, 锂金属表面形 成了很好的 SEI 膜, 锂枝晶问题得到了改善, 循环 过程中库伦效率可以达到 $99 \%$ 。

常规 $\mathrm{LiPF}_{6}$ 电解液锂金属电池, 大倍率充放电 时 $\mathrm{Li}$ 金属表面容易生成较厚的电解质膜, 阻抗值大 幅上升, 容量衰减严重。Xiang 等 ${ }^{[56]}$ 将 LiTFSI/LiBOB 电解液应用于 $\mathrm{LiNi}_{0.8} \mathrm{Co}_{0.15} \mathrm{Al}_{0.05} \mathrm{O}_{2}$ 锂金属电池, 电 流密度为 $1.50 \mathrm{~mA} \cdot \mathrm{cm}^{-2}$, 放电比容量达 $131 \mathrm{mAh} / \mathrm{g}$, 且 100 圈后容量保留率保持在 $80 \%$ 以上。该多盐体 系电解液电池性能优异的原因在于其成膜性能, 在 锂金属表面形成厚度较薄且电导率高的 SEI 膜(图 4)。

在电解液中使用两种或多种锂盐, 通过锂盐之 间的复合协同作用，可以弥补 $\mathrm{LiPF}_{6}$ 和其它锂盐的 不足, 进而开发出满足应用需求的新型电解液体系, 即多盐体系电解液。多盐体系电解液具备了单一锂 盐电解液不具有的特性。

\section{2 高浓度锂盐电解液的研究}

\subsection{1 高浓度电解液的定义及发展历程}

当电解液中锂盐浓度提升至 $3 \mathrm{~mol} / \mathrm{L}$ 以上时, 溶剂
分子与 $\mathrm{Li}^{+}$的配位数会减少至 1 2 个, 且溶液中几乎 不存在自由溶剂分子, 锂盐通常以 AGGs 和 CIPs 形 式存在, 此种电解液被称为高浓度电解液。高浓度 电解液中自由溶剂分子数较少且受离子络合作用影 响, 通常具备许多不寻常特性, 对于高浓度电解液 的研究主要包括两方面: 界面反应和主体性质。

锂离子电池界面反应包括锂离子的嵌入/脱出、 电解液的分解和 SEI 膜的形成等过程。界面反应对 电池容量性能、循环性能、化学和物理稳定性等有 重要影响。1985 年 Mckinnon 等 ${ }^{[57]}$ 报道达到饱和浓 度的 $\mathrm{LiAsF}_{6} / \mathrm{EC}$ 基电解液, 可抑制溶剂分子嵌入层 状 $\mathrm{ZrS}_{2}$ 电极。2003 年 Jeong 等 ${ }^{[58]}$ 发现高浓度 PC 基 电解液中, $\mathrm{Li}^{+}$在石墨负极能进行可逆脱出/嵌入反 应。Jeong 等 ${ }^{[59]}$ 又在 2008 年报道 PC 基高浓度电解 液能有效抑制 $\mathrm{Li}$ 金属电极上锂枝晶生成。Suo 等 ${ }^{[60]}$ 和 Qian 等 ${ }^{[61]}$ 分别在 2013 年和 2015 年报道了高浓 度电解液能使锂金属电池具备良好的可逆性能, 有 效抑制 Li-S 电池中锂多硫化合物溶解。Matsumoto 等 ${ }^{[62]}$ 则在 2013 年报道了高浓度锂盐电解液能够抑 制 $\mathrm{Al}$ 集流体腐蚀。

对于高浓度电解液主体性质的研究表明，一些 锂盐和溶剂的高浓度混合物已不是简单的 “溶液”, 它具备类似于离子液体的特殊性质。2001 年, Liang $^{[63]}$ 等利用 LiTFSI 和尿素配制成高浓度电解质, 虽然是由两种固体组成, 但其在常温下以液态存在, 认为是两物质间的强相互作用减弱了 LiTFSI 阴阳 离子间的结合力, 形成了一种低共熔盐。同时, Henderson 等 ${ }^{[64]}$ 使用 LiTFSI 作为锂盐, 四乙二醇二 甲醚为溶剂, 该高浓度电解质在常温下以离子液体 形式存在电化学窗口可达到 $4.5 \mathrm{~V}$ 以上 $\left(v s . \mathrm{Li}^{+} / \mathrm{Li}\right)$ 。 2010 年开始, Watanabe 等 ${ }^{[65-67]}$ 的一系列文章报道了 高浓度电解液许多类似于离子液体的物理化学性质, 并将其定义为一种新型的离子液体溶剂化物。

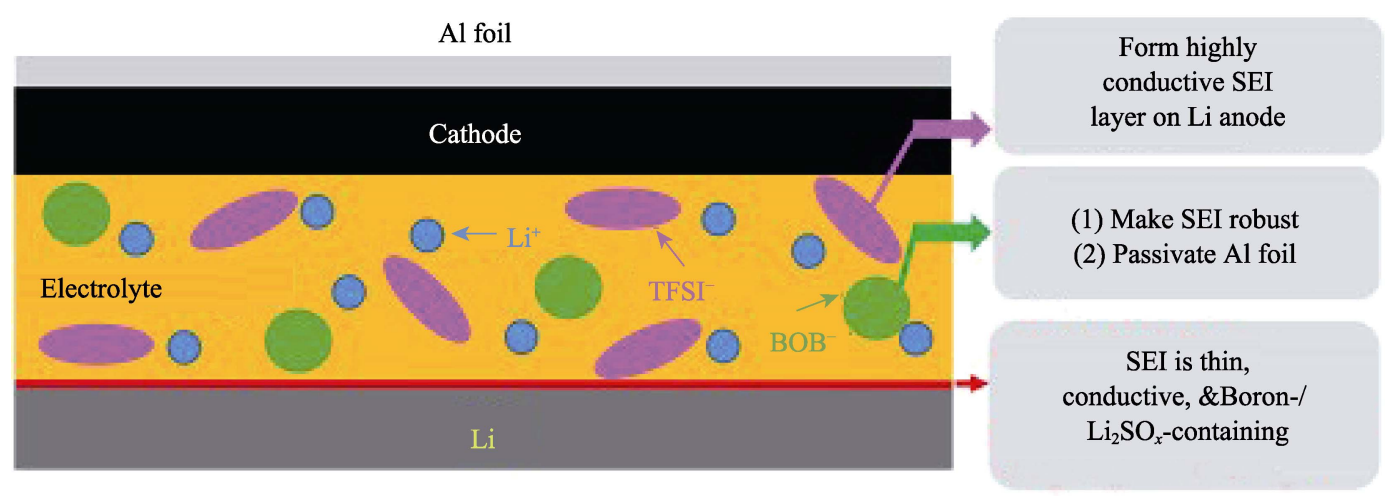

图 4 LiTFSI 和 LiBOB 在多盐体系电解液中的作用 ${ }^{[56]}$

Fig. 4 Schematic illustration of the effects of LiTFSI and LiBOB in dual-salt electrolyte ${ }^{[56]}$ 


\subsection{2 高浓度电解液的物理化学特性}

高浓度锂盐电解液受溶剂化作用影响, 区别于 常规电解液, 具备了诸多不寻常的特点。其性能优 点可概括为:

(1)耐还原性增强 ${ }^{[68]}$ 。高浓度电解液中阴离子容 易被还原成为 SEI 膜主要成分，使 SEI 膜更稳定。

(2)耐氧化性增强 ${ }^{[69]}$ 。能有效抑制电解液在高电 位下的氧化分解，提高库伦效率。

(3)抑制铝箔腐蚀。不使用 $\mathrm{LiPF}_{6}$ 情况下，也能 很好地抑制 $\mathrm{Al}$ 集流体的腐蚀 ${ }^{[70]}$ 。

(4)热稳定性增强。大幅降低电解液挥发性, 提 高热力学稳定性, 改善电池安全性能。

(5)锂离子迁移数提高。电荷传输过程中具有较 大的锂离子迁移数。

(6)抑制多硫化物溶解和迁移，降低穿梭效应对 电池性能的影响, 提高锂硫电池的循环稳定性。

但高浓度电解液黏度较高, 对电极等界面的润 湿性较差, 且由于特殊的溶剂化结构, 降低了锂离 子的迁移活性，电导率较低。同时，锂盐价格远高于 溶剂, 使成本大幅上升。接下来对高浓度电解液的 各项性能进行详细介绍。

\subsection{3 高浓度电解液的优异性能}

(1)防止石墨剥离

含 $\mathrm{EC}$ 溶剂电解液能在石墨负极表面形成含 $\mathrm{LiF}$ 的稳定 $\mathrm{SEI}$ 膜, 避免 $\mathrm{Li}^{+}$溶剂化合物在石墨层的 共嵌 ${ }^{[71]}$ (图 5)。但 EC 存在高黏度、高熔点的缺点, 影 响电池低温性能和快速充放电性能。通过提高电解 液中锂盐浓度, 可以使石墨电极在不含 $\mathrm{EC}$ 溶剂的 电解液中具备良好兼容性。

$\mathrm{Nie}$ 等 ${ }^{[72]}$ 采用不同浓度 $\mathrm{LiPF}_{6} / \mathrm{PC}$ 电解液, 对电 池性能展开研究。在 $1.2 \mathrm{~mol} / \mathrm{L} \mathrm{LiPF} / \mathrm{PC}$ 电解液中, 电解液持续分解, $\mathrm{Li}^{+}$在石墨电极中嵌入/脱出反应 不可逆, $\mathrm{Li}^{+}$主要以 $\mathrm{Li}^{+}(\mathrm{PC})_{4} / \mathrm{PF}_{6}{ }^{-}$溶剂化合物(SSIPs) 存在, 且电解液分解产物主要为丙烯碳酸锂(LPDC),

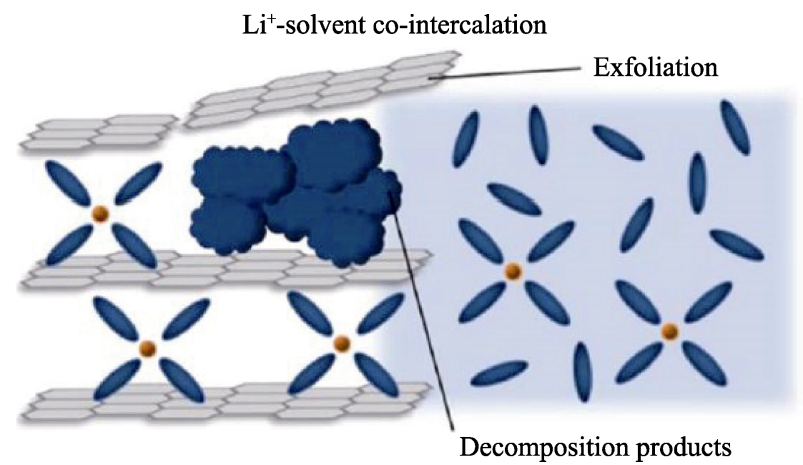

图 $5 \mathrm{Li}^{+}$溶剂化合物共嵌导致石墨层的剥离 ${ }^{[2]}$

Fig. 5 The exfoliation of graphite layers caused by $\mathrm{Li}^{+}$-solvent co-intercalation ${ }^{[2]}$
如图 6。成分为碳酸盐的 SEI 膜热稳定性较差, 所以 稀浓度电解液电池循环性能衰减严重。电解液浓度 升至 $3.5 \mathrm{~mol} / \mathrm{L}$ 时, $\mathrm{Li}^{+}$主要以 $\mathrm{Li}^{+}(\mathrm{PC})_{3} \mathrm{PF}_{6}{ }^{-}$溶剂化合 物(CIPs) 存在。电极表面形成致密 SEI 膜, 主要成分 为 $\mathrm{LiF}$, 热力学稳定性良好, $\mathrm{Li}^{+}$在石墨电极上可进 行可逆嵌入/脱出反应。

(2)改善倍率性能

随着电动汽车快速发展, 为提高充电效率, 锂 离子电池快充技术被提上议程。Yamada 等 ${ }^{[68]}$ 发现 高浓度 (3.6 mol/L)LiFSA/DME(1,2-二甲氧基乙烷) 电解液中, $\mathrm{Li}^{+}$在石墨负极可进行快速嵌入/脱出反 应。而在稀浓度 $\mathrm{LiFSI} / \mathrm{DME}$ 电解液中, $\mathrm{Li}^{+}$-溶剂分子 共嵌导致石墨层剥离, 容量大幅衰减。该电解液电 池倍率性能优异(图 7), 原因可归纳为: (1)良好的界 面膜促进 $\mathrm{Li}^{+}$嵌入/脱出反应; (2)电化学双电层界面 中的 $\mathrm{Li}^{+}$浓度较高; (3) 该电解液的 $\mathrm{Li}^{+}$迁移数较大。

(3)抑制铝箔腐蚀

磺酰亚胺类锂盐(如 LiFSI、LiTFSI 等)的离子电
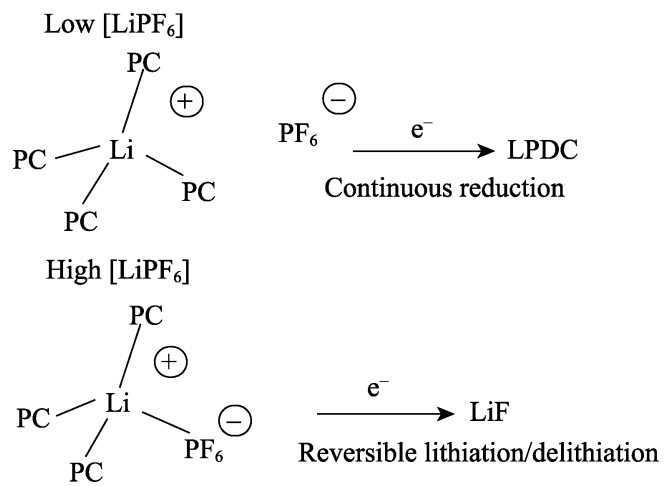

图 6 低浓度和高浓度电解液中 SEI 膜的主要成分 ${ }^{[72]}$

Fig. 6 The main components of SEI in dilute and concentrated electrolytes ${ }^{[72]}$

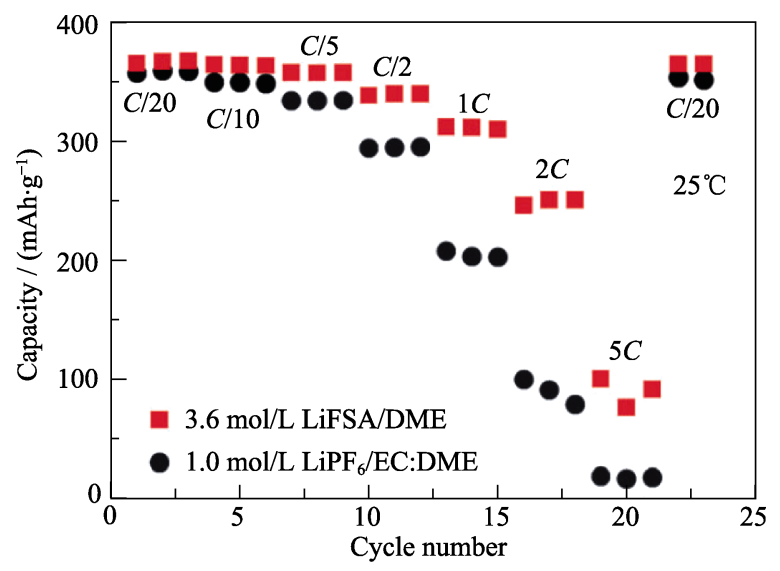

图 7 石墨/Li 金属半电池在两种电解液中不同充放电倍率 下的可逆容量 ${ }^{[68]}$

Fig. 7 Reversible capacity of a natural graphite/Li half cell with two electrolytes at various $\mathrm{C}$-rates ${ }^{[68]}$ 
导率较高, 热稳定性和电化学稳定性较高。但该类 锂盐电解液的 $\mathrm{Al}$ 腐蚀问题严重。研究人员发现高浓 度磺酰亚胺类锂盐电解液可抑制 $\mathrm{Al}$ 箔腐蚀。

Matsumoto 等 ${ }^{[73]}$ 对抑制 Al 腐蚀进行了解释, XPS(X 射线光电子能谱分析)测试发现高浓度电解 液中 $\mathrm{Al}$ 筞表面形成了一层 $\mathrm{LiF}$ 针化膜, 是抑制 $\mathrm{Al}$ 腐蚀的根本原因。高浓电解液中 LiTFSI 的解离度小, 溶液中 $\mathrm{Li}^{+}$和 $\mathrm{TFSI}^{-}$阴离子间距离较近, 在 $\mathrm{Al}$ 簿表面 $\mathrm{TFSI}^{-}$的氧化产物 $\mathrm{F}^{-}$更易与 $\mathrm{Li}^{+}$结合生成 $\mathrm{LiF}$ 钝化膜 (图 8)。

Henderson 等 ${ }^{[74]}$ 提出了不同观点, 认为 $\mathrm{TFSI}^{-}$阴 离子中 $\mathrm{C}-\mathrm{F}$ 键很稳定, 不易氧化生成 $\mathrm{F}^{-}$。抑制 $\mathrm{Al}$ 腐蚀原因并不在于 $\mathrm{LiF}$ 针化膜的生成, 是由于该电 解液中自由溶剂分子数较少, 且 $\mathrm{Al}(\mathrm{TFSI})_{3}$ 复合物溶 解度较低, 很难在电解液中扩散。

\section{(4)保护金属锂沉积溶出}

$\mathrm{Li}$ 金属电池存在的问题阻碍了其实际应用。研 究表明, 提升电解液锂盐浓度可在 $\mathrm{Li}$ 金属表面形成 稳定 SEI 膜, 提高电极稳定性和电池库伦效率。

Yoon 等 ${ }^{[75]}$ 采用 $3.27 \mathrm{~mol} / \mathrm{L} \mathrm{LiBETI}$ (双五氟乙磺 酰亚胺锂)/PC 高浓度电解液, 发现 $\mathrm{Li}$ 金属表面 SEI 膜能有效抑制锂枝晶生长。形成的 SEI 膜厚度较薄, 且该电解液体系电池电化学性能优异。

Qian 等 ${ }^{[61]}$ 使用 LiFSI/DME 高浓度电解液, 大倍 率充放电时电池的库伦效率较高, $\mathrm{Li}$ 金属表面无锂 枝晶生成。原因是高浓度电解液中溶剂分子均以络 合形式存在, 减弱了电解液与 $\mathrm{Li}$ 金属间的副反应, 同时还促进了 SEI 膜的形成。

(5)高浓度水系电解液的应用

水系电解液作为一种不易燃且绿色环保的电解 液体系, 在储能领域受到广泛关注。但水系电解液 (a) $1.0 \mathrm{~mol} / \mathrm{L} \mathrm{LiTFSI}$

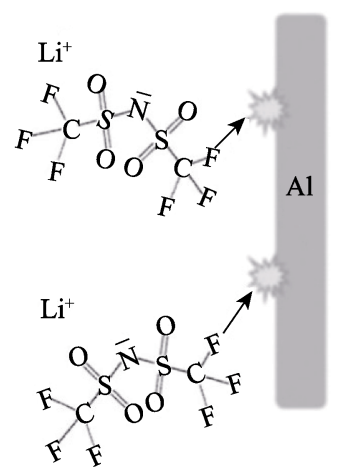

(b) $1.8 \mathrm{~mol} / \mathrm{L}$ LiTFSI

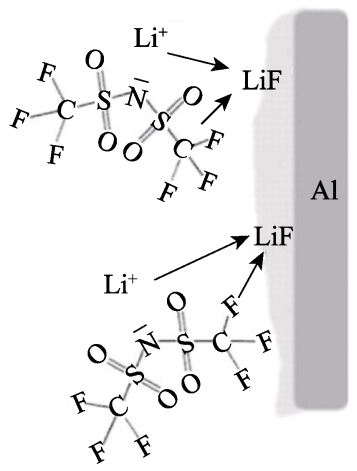

图 8 不同浓度电解液中 LiTFSI 锂盐的分解机理和 LiF 电解 质膜的形成机理(a) $1.0 \mathrm{~mol} / \mathrm{L} \mathrm{LiTFSI}$ 和(b)1.8 mol/L LiTFSI ${ }^{[73]}$

Fig. 8 Mechanism for LiTFSI decomposition and formation of LiF film in (a) $1.0 \mathrm{~mol} / \mathrm{L} \mathrm{LiTFSI} \mathrm{and} \mathrm{(b)} 1.8 \mathrm{~mol} / \mathrm{L} \mathrm{LiTFSI}^{[73]}$
中由于 $\mathrm{H}_{2} 、 \mathrm{O}_{2}$ 等的生成, 电极表面很难形成致密 SEI 膜。且其电化学稳定窗口通常较窄 $(1.5 \mathrm{~V})$, 限 制了电池能量密度提升。

Suo 等 ${ }^{[76]}$ 提出了一种高浓度水系电解液 “Water-in-salt”, 该电解液的电化学稳定窗口较宽, 水反应活性较低。电解液中极高的离子密度抑制了 水的反应，并形成了一层更具保护作用的 SEI 膜。

在此基础上, Suo 等 ${ }^{[77]}$ 又在上述电解液体系中 引入第二种锂盐。该高浓度 $(28 \mathrm{~mol} / \mathrm{L})$ 水系电解液包 含 $21 \mathrm{~mol} / \mathrm{L}$ 的 LiTFSI 和 $7 \mathrm{~mol} / \mathrm{L}$ 的 LiOTF(三氟甲 磺酸锂)。该电解液可在电极表面生成更有效的电解 质膜, 抑制电极表面水分解。使用 $\mathrm{LiMn}_{2} \mathrm{O}_{4}$ 为正极, $\mathrm{TiO}_{2}$ 为负极, 该电池具有 $2.5 \mathrm{~V}$ 的电化学窗口, 能量 密度达 $100 \mathrm{Wh} / \mathrm{kg}$, 库伦效率和循环稳定性均较高。

\subsection{4 高浓度电解液的优异性能原因分析}

高浓度电解液具备的独特界面化学性质和优异 电化学性能, 可通过电极表面 SEI 膜的形成过程作 出合理解释。高浓度和较稀浓度电解液中 SEI 膜形 成过程是有区别的, 这种差异是由不同的 $\mathrm{Li}^{+}$溶剂 化状态导致(图 9(a))。稀浓度电解液 SEI 膜组成主要 来自被分解的电解液溶剂(图 9(b))。而高浓度电解 液 ( $>3.0 \mathrm{~mol} / \mathrm{L})$, 锂盐阴离子参与 $\mathrm{Li}^{+}$溶剂化作用, SEI 膜中含一定比例的锂盐阴离子组分(图 9(c))。

高浓度电解液形成比较稳定的 SEI 膜, 不易造 成石墨的剥离, 并有助于金属锂的长期稳定循环。 高浓度电解液中溶剂分子均参与了锂离子的溶剂化, (a)

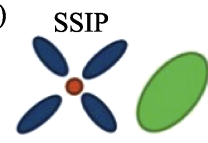

(b)

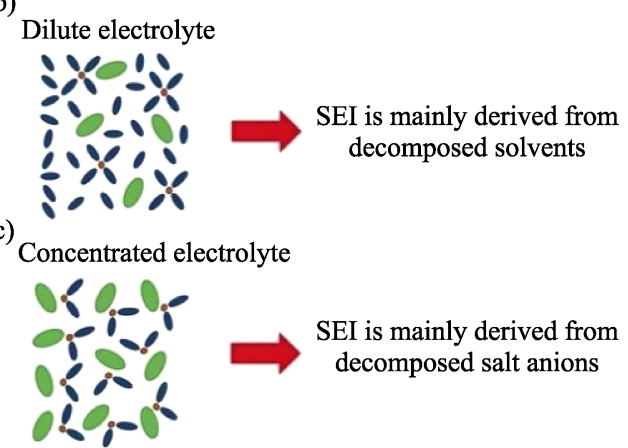

图 9 (a)稀浓度和高浓度电解液中不同的 $\mathrm{Li}^{+}$溶剂化作用形 式(SSIPs、CIPs 和 AGGs)(b)稀浓度和(c)高浓度电解液中电 极表面发生的界面反应 ${ }^{[78]}$

Fig. 9 (a) Representative $\mathrm{Li}^{+}$cation solvate species (SSIPs, CIPs and AGGs) in dilute and concentrated electrolytes. Schematic illustration of the electrolyte reduction mechanism at the electrode/electrolyte interface in (b) dilute and (c) concentrated electrolytes ${ }^{[78]}$ 
使溶剂难以挥发, 降低了电解液的可燃性。阴离子 也参与了锂离子的溶剂化, 使阴离子的迁移得到抑 制, 从而有效增加锂离子迁移数, 并且电解液中锂 离子密度增大, 进而提高电池倍率性能。同时, 高浓 度电解液中溶液接近饱和状态, 所以大幅抑制需要 溶解才能发生的副反应，如氧化、铝箔腐蚀和多硫 化锂的溶解造成的穿梭效应。

前线轨道理论是电解液开发的有力工具, 可对 高浓度电解液溶剂化状态改变及电极表面 SEI 膜形 成机理作出合理解释。前线轨道理论认为 ${ }^{[78]}$ : 物质 在反应过程中, 发生相互作用的是分子轨道, 而优 先起作用的是前线轨道, 前线轨道在很大程度上反 映了物质的理化性质。 $\mathrm{HOMO}$ (分子最高占据轨道能 量)越高, 轨道中的电子越不稳定, 越容易失去而被 氧化; 相反, LUMO(分子最低未占据轨道能量)越低, 越容易得到电子而被还原。采用 DFT(密度泛函理 论), 利用 $\mathrm{MD}$ (分子动力学模拟)方法, 可以计算出 某一分子结构的 HOMO/LUMO 值, 从理论上解释 高浓度电解液不同寻常的界面性质和优异的电化学 性能, 这对高浓度电解液的研究开发具有重要意义。

Yamada 等 ${ }^{[78]}$ 采用 DFT-MD 模拟计算方法, 对 高浓度 $(4.2 \mathrm{~mol} / \mathrm{L}$ )LiTFSA/AN(乙腈)电解液中 SEI 膜含锂盐阴离子成分的原因进行了深入研究。稀浓 度 $(0.4 \mathrm{~mol} / \mathrm{L})$ 电解液中, 锂盐充分解离, $\mathrm{AN}$ 分子的 最低导带能量要低于 $\mathrm{TFSA}^{-}$, LUMO 位于 AN 分子 上(图 10(a))。而电解液浓度上升至 $4.2 \mathrm{~mol} / \mathrm{L}$ 时, LUMO 从 AN 分子转移至 TFSA'(图 10(b)), TFSA 会优先在石墨负极表面发生反应, SEI 膜中含比例 较高的 LiF 成分, 形成一层致密的 SEI 界面膜, 有效 提高电池电化学性能和安全性能。

\subsection{5 针对高浓度电解液的问题改进方法}

目前高浓度电解液面临一系列问题:

(1)电导率很低, 影响电池倍率性能;

(2)在低温下容易析出锂盐，造成其低温性能差;

(3)黏度较高, 很难润湿电池隔膜;

(4)锂盐的比例升高, 大幅提高成本。

未来研究应着手解决这些问题, 并实现较低锂 盐浓度也能使电解液具备优良成膜性能。

引入惰性溶剂(黏度低、不与 $\mathrm{Li}^{+}$产生溶剂化作 用、电化学稳定性较高)作为稀释剂, 可降低电解液 黏度、拓宽工作温度区间、改善对隔膜润湿能力和 降低生产成本。Doi 等 ${ }^{\left[{ }^{[9]}\right.}$ 为降低电解液黏度, 尝试 使用多种氟代烷基醚作为稀释剂加入到高浓度 (3.75 mol $/ \mathrm{kg}) \mathrm{LiBF}_{4} / \mathrm{PC}$ 电解液中。其中, $\mathrm{LiBF}_{4}$ 在 $\operatorname{HFE}(1,1,2,2$-四氟乙基-2,2,3,3-四氟丙基醚)中有较 高溶解度。加入适量 HFE 使电解液浓度降至 (a) Dilute solution (dissociated)
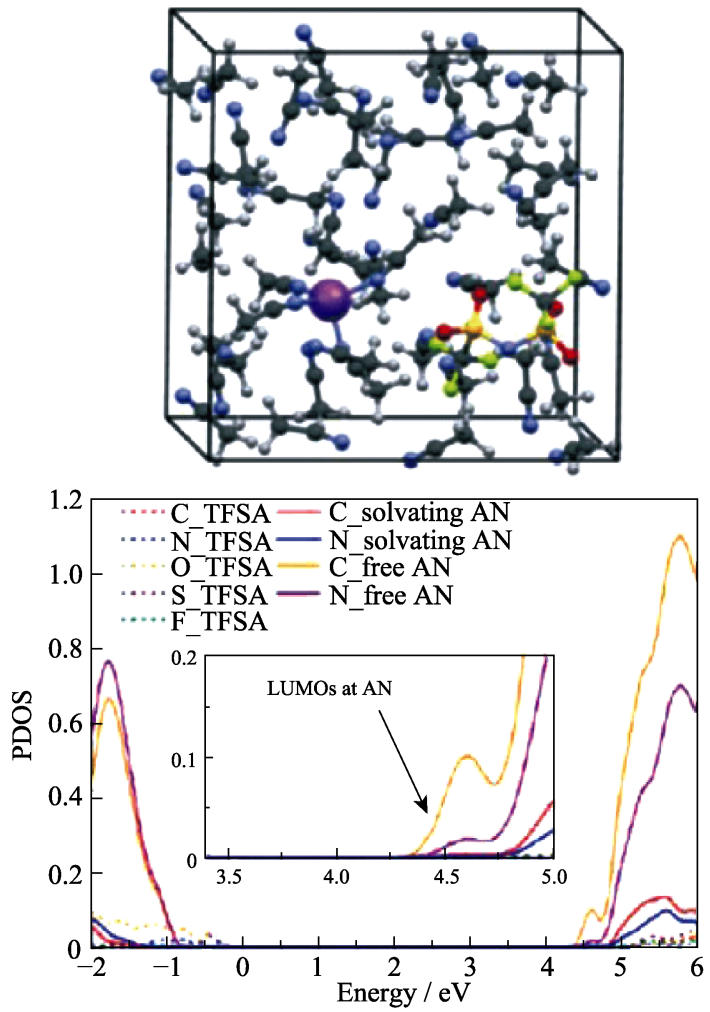

(b) Superconcentrated solution
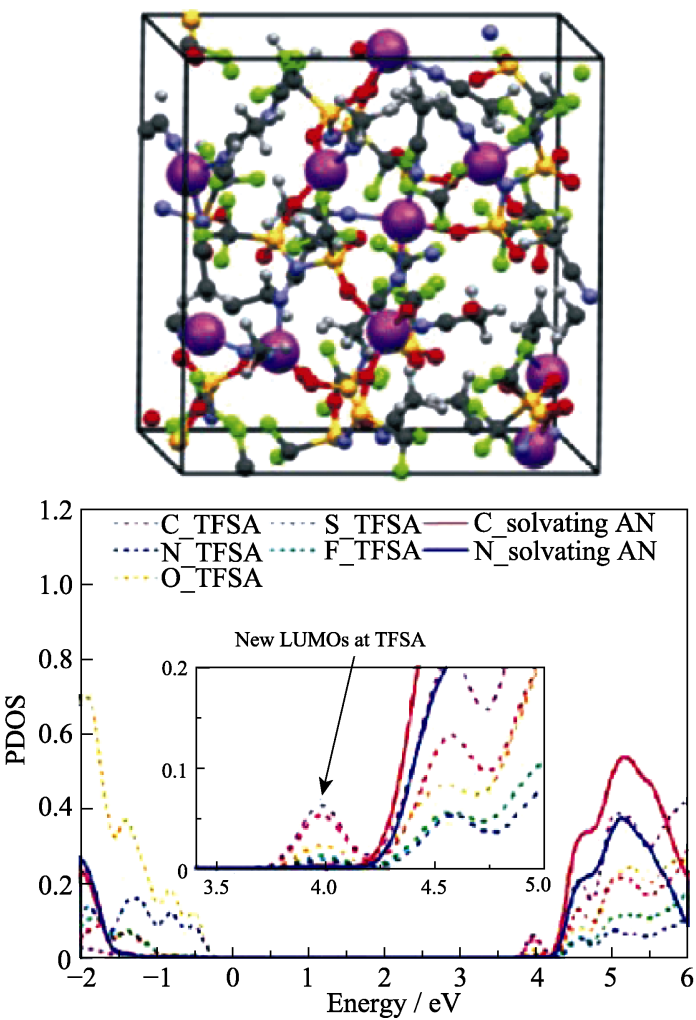

图 $10 \mathrm{Li}^{+}$溶剂化结构模型和通过 DFT-MD 模拟计算得到的 PDOS 值(a)稀浓度电解液(b)高浓度电解液 ${ }^{[78]}$

Fig. 10 Supercells used and projected density of states (PDOS) obtained in quantum mechanical DFT-MD simulations on non-aqueous (a) dilute $(0.4 \mathrm{~mol} / \mathrm{L})$ and (b) superconcentrated $(4.2 \mathrm{~mol} / \mathrm{L})$ LiTFSA/AN solutions ${ }^{[78]}$

$2.5 \mathrm{~mol} / \mathrm{kg}$, 此时电解液不仅具有较低的黏度, 且保 
持了高浓度电解液的成膜性能, 使电池在高电压下 依然具有优异的氧化稳定性。此外, 根据高浓度电 解液的溶剂化作用状态和成膜原理, 可加入一些能 在电极表面吸附的添加剂, 以优化电极表面的双电 层, 从而对 SEI 膜组成进行调控, 这种方法更容易 得到工业化的应用。

\section{3 总结及展望}

电解液配方设计对电池循环寿命、倍率性能、 适用温度和安全性等都具有重要影响。锂盐作为电 解液中锂离子的提供者, 显著影响电解液的性能。 因在电导率、稳定性和成本等方面具有良好的综合 性能, $\mathrm{LiPF}_{6}$ 是当前应用最为广泛的锂盐。但 $\mathrm{LiPF}_{6}$ 有热稳定性差、对水敏感等缺点, 因而寻找各项性 能优异的新型锂盐成为当前研究的重点。于是, 先 后提出了 $\mathrm{LiBF}_{4} 、 \mathrm{LiBOB} 、 \mathrm{LiTFSI} 、 \mathrm{LiFSI} 、 \mathrm{LiPO}_{2} \mathrm{~F}_{2}$ 和 LiTDI 等新型锂盐, 这些锂盐虽然能避免 $\mathrm{LiPF}_{6}$ 的缺点, 却在电导率、铝䈃腐蚀和价格方面存在问 题。因此, 至今尚且没有任何一种锂盐能够完全替 代 $\mathrm{LiPF}_{6}$ 。

多盐体系电解液和高浓度电解液以其特殊的性 质摆脱了经典的 $\mathrm{LiFP}_{6}-\mathrm{EC}$ 设计体系, 使电解液配方 中的锂盐和溶剂有了更多的选择, 从而进一步提升 了电解液的性能。其中, 多盐体系电解液结合不同 锂盐的优点, 克服了单一锂盐的缺点, 使电解液具 备优异的电化学性能; 高浓度电解液则是通过改变 锂离子的溶剂化状态, 使其具有更宽的电化学窗口 和更好的安全性, 同时具有防止石墨剥离、提高金 属锂循环稳定性和抑制铝䈃腐蚀等优点。因此, 在 多盐体系电解液和高浓度电解液中可以有针对性的 选择电导率高或是某种性能突出的锂盐, 通过锂盐 和溶剂的合理配置以实现锂离子电池高能量密度及 快速充放电的能力。两种新型电解液以其独特的优 势, 有很大的潜力实现对现有电池技术的变革。

本课题组调研了高浓度电解液的相关研究, 发 现高浓度电解液一系列的优点都来源于其特殊的溶 剂化结构。但是, 其黏度高、界面浸润性差和电导 率低的缺点都是因为其铰链的溶液结构。因此, 本 课题组研究高浓度电解液的思路是在不改变高浓度 电解液锂离子溶剂化结构的基础上, 打乱其铰链的 溶液结构 ${ }^{[80]}$ 。具体来说, 就是在高浓度电解液中引 入非溶剂液体, 非溶剂液体不能溶解锂盐, 因而不 会改变锂离子的溶剂化结构。但非溶剂液体的引入 打乱了高浓度电解液中铰链的溶液结构, 可以明显 降低电解液黏度和改善界面润湿性, 提高锂离子电
导率。同时, 由于锂盐在电解液中整体浓度的降低, 这种新型的电解液还能降低电解液成本。相信这一 方法有助于推动高浓度电解液的规模应用, 并为其 它体系电解液的设计提供思路。

\section{参考文献:}

[1] 问春生, 李媛媛, 刘园园. 锂离子电池电解质锂盐的发展历程 和新型锂盐的研究进展. 河南化工, 2016, 33(4): 14-17.

[2] YAMADA Y, YAMADA A. Review-superconcentrated electrolytes for lithium batteries. Journal of The Electrochemical Society, 2015, 162(14): A2406-A2423.

[3] 吴宇平. 锂离子电池: 应用与实践, 2 版. 北京: 化学工业出版 社, 2012.

[4] 李永坤, 张若听, 刘建生. 锂离子电池电解液稳定添加剂研究 进展. 电池工业, 2008, 13(5): 353-356.

[5] 刘 旭, 杨续来. 锂离子电池电解质锂盐的研究进展. 电源技术, 2016, 40(1): 218-220.

[6] YANG H, ZHUANG G V, JR P N R. Thermal stability of $\mathrm{LiPF}_{6}$ salt and Li-ion battery electrolytes containing $\mathrm{LiPF}_{6}$. Journal of Power Sources, 2006, 161(1): 573-579.

[7] RAVDEL B, ABRAHAM K M, GITZENDANNER R, et al. Thermal stability of lithium-ion battery electrolytes. Journal of Power Sources, 2003, s119-121: 805-810.

[8] KAWAMURA T, OKADA S, YAMAKI J I. Decomposition reaction of $\mathrm{LiPF}_{6}$-based electrolytes for lithium ion cells. Journal of Power Sources, 2006, 156(2): 547-554.

[9] PLAKHOTNYK A V, ERNST L, SCHMUTZLER R. Hydrolysis in the system $\mathrm{LiPF}_{6}$-propylene carbonate-dimethyl carbonate- $\mathrm{H}_{2} \mathrm{O}$. Journal of Fluorine Chemistry, 2005, 126(1): 27-31.

[10] PARK C K, ZHANG Z, XU Z, et al. Variables study for the fast charging lithium ion batteries. Journal of Power Sources, 2007, 165(2): 892-896.

[11] LUX S F, LUCAS I T, POLLAK E, et al. The mechanism of HF formation in $\mathrm{LiPF}_{6}$ based organic carbonate electrolytes. Electrochemistry Communications, 2012, 14(1): 47-50.

[12] 庄全超, 徐守冬, 邱祥云, 等. 锂离子电池的电化学阻抗谱分析. 化学进展, 2010, 22(6): 1044-1057.

[13] 宋印涛, 李连仲, 丁 静, 等. 锂离子电池电解质盐的研究进展. 浙江化工, 2010, 41(8): 24-26.

[14] ARAVINDAN V, GNANARAJ J, MADHAVI S, et al. Lithium-ion conducting electrolyte salts for lithium batteries. Chemistry, 2011, 17(51): 14326-14346.

[15] KAWAMURA T, KIMURA A, EGASHIRA M, et al. Thermal stability of alkyl carbonate mixed-solvent electrolytes for lithium ion cells. Journal of Power Sources, 2002, 104(2): 260-264.

[16] XU K. Nonaqueous liquid electrolytes for lithium-based rechargeable batteries. Chemical Reviews, 2004, 104(10): 4303-4418.

[17] ZHANG S S, XU K, JOW T R. A new approach toward improved low temperature performance of Li-ion battery. Electrochemistry Communications, 2002, 4(11): 928-932.

[18] ZHANG Z A, ZHAO X X, PENG B, et al. Mixed salts for lithium iron phosphate-based batteries operated at wide temperature range. Transactions of Nonferrous Metals Society of China, 2015, 25(7): 2260-2265.

[19] KOMABA S, ISHIKAWA T, YABUUCHI N, et al. Fluorinated ethylene carbonate as electrolyte additive for rechargeable $\mathrm{Na}$ batteries. ACS Applied Materials \& Interfaces, 2011, 3(11): 41654168. 
[20] LI Y, LIAN F, MA L, et al. Fluoroethylene carbonate as electrolyte additive for improving the electrochemical performances of highcapacity $\mathrm{Li}_{1.16}\left[\mathrm{Mn}_{0.75} \mathrm{Ni}_{0.25}\right]_{0.84} \mathrm{O}_{2}$ material. Electrochimica Acta, 2015, 168: 261-270.

[21] ZHANG S S, XU K, JOW T R. Enhanced performance of Li-ion cell with $\mathrm{LiBF}_{4}-\mathrm{PC}$ based electrolyte by addition of small amount of LiBOB. Journal of Power Sources, 2006, 156(2): 629-633.

[22] 蒲薇华, 何向明, 王 莉, 等. 锂离子电池 LiBOB 电解质盐研究. 化学进展, 2006, 18(12): 1703-1709.

[23] XU K, ZHANG S S, LEE U, et al. LiBOB: is it an alternative salt for lithium ion chemistry? Journal of Power Sources, 2005, 146(1): 79-85.

[24] ZHANG S S. Electrochemical study of the formation of a solid electrolyte interface on graphite in a $\mathrm{LiBC}_{2} \mathrm{O}_{4} \mathrm{~F}_{2}$-based electrolyte. Journal of Power Sources, 2007, 163(2): 713-718.

[25] ZHANG S S. An unique lithium salt for the improved electrolyte of Li-ion battery. Electrochemistry Communications, 2006, 8(9): 1423-1428.

[26] 邓凌峰, 陈 洪. 锂电池用草酸二氟硼酸锂有机电解液的电化学 性能. 无机化学学报, 2009, 25(9): 1646-1650.

[27] KANAMURA K, UMEGAKI T, SHIRAISHI S, et al. Electrochemical behavior of $\mathrm{Al}$ current collector of rechargeable lithium batteries in propylene carbonate with $\mathrm{LiCF}_{3} \mathrm{SO}_{3}, \mathrm{Li}\left(\mathrm{CF}_{3} \mathrm{SO}_{2}\right)_{2} \mathrm{~N}$, or $\mathrm{Li}\left(\mathrm{C}_{4} \mathrm{~F}_{9} \mathrm{SO}_{2}\right)$ $\left(\mathrm{CF}_{3} \mathrm{SO}_{2}\right) \mathrm{N}$. Journal of the Electrochemical Society, 2002, 149(2): A185-A194.

[28] 胡锋波, 张庆华, 詹晓力, 等. 双(氟代磺酰)亚胺及其盐的制 备、性能与应用进展. 化工进展, 2011, 30(10): 2097-2105.

[29] YANG G, SHI J, SHEN C, et al. Improving the cyclability performance of lithium-ion batteries by introducing lithium difluorophosphate $\left(\mathrm{LiPO}_{2} \mathrm{~F}_{2}\right)$ additive. RSC Advances, 2017, 7(42): 26052-26059.

[30] NIEDZICKI L, GRUGEON S, LARUELLE S, et al. New covalent salts of the $4^{+} \mathrm{V}$ class for Li batteries. Journal of Power Sources, 2011, 196(20): 8696-8700.

[31] PAIlleT S, SCHMIDT G, LADOUCEUR S, et al. Power capability of LiTDI-based electrolytes for lithium-ion batteries. Journal of Power Sources, 2015, 294: 507-515.

[32] YOUNESI R, VEITH G M, JOHANSSON P, et al. Lithium salts for advanced lithium batteries: Li-metal, $\mathrm{Li}_{-} \mathrm{O}_{2}$, and Li-S. Energy \& Environmental Science, 2015, 8(7): 1905-1922.

[33] HAN H B, ZHOU S S, ZHANG D J, et al. Lithium bis(fluorosulfonyl) imide (LiFSI) as conducting salt for nonaqueous liquid electrolytes for lithium-ion batteries: physicochemical and electrochemical properties. Journal of Power Sources, 2011, 196(7): 3623-3632.

[34] TAN S, JI Y J, ZHANG Z R, et al. Recent progress in research on high-voltage electrolytes for lithium-ion batteries. ChemPhysChem, 2014, 15(10): 1956-1969.

[35] ABOUIMRANE A, DING J, DAVIDSON I J. Liquid electrolyte based on lithium bisfluorosulfonyl imide salt: aluminum corrosion studies and lithium ion battery investigations. Journal of Power Sources, 2009, 189(1): 693-696.

[36] 谭晓兰, 程新群, 马玉林, 等. LiBOB 基电解液成膜性及其循环 性能. 物理化学学报, 2009, 25(10): 1967-1971.

[37] 秦利平, 郭为民. 新型锂盐二氟草酸嗍酸锂的研究进展. 电源 技术, 2014, 38(6): 1159-1161.

[38] Sigma-Aldrich, http://www.sigmaaldrich.com/materialsscience/materialscience-products.html? TablePage $=19295337$.

[39] HU Y, LI H, HUANG X, et al. Novel room temperature molten salt electrolyte based on LiTFSI and acetamide for lithium batteries. Electrochemistry Communications, 2004, 6(1): 28-32.

[40] YANG L, ZHANG H, DRISCOLL P, et al. Six-membered-ring malonatoborate-based lithium salts as electrolytes for lithium ion batteries. ECS Transactions, 2011, 33(39): 57-69.

[41] 戴立新. 高氯酸锂有机电解液的制备研究. 新疆有色金属, 2007, 30(A01):98-99.

[42] SEO D M, BORODIN O, HAN S D, et al. Electrolyte solvation and ionic association. Journal of the Electrochemical Society, 2012 , 161(14): A2042-A2053.

[43] XU KANG. "Charge-transfer" process at graphite/electrolyte interface and the solvation sheath structure of $\mathrm{Li}^{+}$in nonaqueous electrolytes. Journal of the Electrochemical Society, 2007, 154(3): A162-A167.

[44] CHEN X, XU W, ENGELHARD M, et al. Mixed salts of LiTFSI and $\mathrm{LiBOB}$ for stable $\mathrm{LiFePO}_{4}$-based batteries at elevated temperatures. Journal of Materials Chemistry A, 2014, 2(7): 2346- 2352.

[45] 王青否, 李法强, 贾国凤，等. 混合锂盐 LiTFSI-LiODFB 基电 解液的高温性能. 电池, 2016, 46(4): 1001-1579.

[46] AMINE K, LIU J, BELHAROUAK I. High-temperature storage and cycling of $\mathrm{C}-\mathrm{LiFePO}_{4} /$ graphite Li-ion cells. Electrochemistry Communications, 2005, 7(7): 669-673.

[47] SONG H, CAO Z, CHEN X, et al. Capacity fade of $\mathrm{LiFePO}_{4} /$ graphite cell at elevated temperature. Journal of Solid State Electrochemistry, 2013, 17(3): 599-605.

[48] 宋海申, 赖延清, 李 劼, 等. $\mathrm{LiPF}_{6} / \mathrm{LiBOB}$ 混合锂盐改善 $\mathrm{LiFePO}_{4} /$ 石墨动力电池高温循环性能研究. 功能材料, 2013, 44(19): 2849-2853.

[49] KIM K E, JANG J Y, PARK I, et al. A combination of lithium difluorophosphate and vinylene carbonate as reducible additives to improve cycling performance of graphite electrodes at high rates. Electrochemistry Communications, 2015, 61: 121-124.

[50] LU Y, TU Z, ARCHER L A. Stable lithium electrodeposition in liquid and nanoporous solid electrolytes. Nature Materials, 2014, 13(10): 961-969.

[51] LIN D, LIU Y, LIANG Z, et al. Layered reduced graphene oxide with nanoscale interlayer gaps as a stable host for lithium metal anodes. Nature Nanotechnology, 2016, 11(7): 626.

[52] BHATT A I, KAO P, BEST A S, et al. Understanding the morphological changes of lithium surfaces during cycling in electrolyte solutions of lithium salts in an ionic liquid. Journal of the Electrochemical Society, 2013, 160(8): A1171-A1180.

[53] XU K. Electrolytes and interphases in Li-ion batteries and beyond. Chemical Reviews, 2014, 114(23): 11503-11618.

[54] JEONG J, LEE J N, PARK J K, et al. Stabilizing effect of 2-(triphenylphosphoranylidene)succinic anhydride as electrolyte additive on the lithium metal of lithium metal secondary batteries. Electrochimica Acta, 2015, 170: 353-359.

[55] MIAO R, YANG J, FENG X, et al. Novel dual-salts electrolyte solution for dendrite-free lithium-metal based rechargeable batteries with high cycle reversibility. Journal of Power Sources, 2014, 271: 291-297.

[56] XIANG H, SHI P, BHATTACHARYA P, et al. Enhanced charging capability of lithium metal batteries based on lithium bis (trifluoromethanesulfonyl)imide-lithium bis(oxalato)borate dual-salt electrolytes. Journal of Power Sources, 2016, 318: 170-177.

[57] MCKINNON W R, DAHN J R. How to reduce the cointercalation of propylene carbonate in $\mathrm{Li}_{\mathrm{x}} \mathrm{ZrS}_{2}$ and other layered compounds. Journal of the Electrochemical Society, 1985, 132(2): 364-366.

[58] JEONG S K, INABA M, IRIYAMA Y, et al. Electrochemical intercalation of lithium ion within graphite from propylene carbonate solutions. Electrochemical and Solid-State Letters, 2003, 6(1): A13-A15.

[59] JEONG S K, SEO H Y, KIM D H, et al. Suppression of dendritic lithium formation by using concentrated electrolyte solutions. Electrochemistry Communications, 2008, 10(4): 635-638. 
[60] SUO L, HU Y S, LI H, et al. A new class of solvent-in-salt electrolyte for high-energy rechargeable metallic lithium batteries. Nature Communications, 2013, 4(2): 1481.

[61] QIAN J, HENDERSON W A, XU W, et al. High rate and stable cycling of lithium metal anode. Nature Communications, 2015, 6: 6362.

[62] MATSUMOTO K, INOUE K, NAKAHARA K, et al. Suppression of aluminum corrosion by using high concentration LiTFSI electrolyte. Journal of Power Sources, 2013, 231(2): 234-238.

[63] LIANG H, LI H, WANG Z, et al. New binary room-temperature molten salt electrolyte based on urea and LiTFSI. The Journal of Physical Chemistry B, 2001, 105(41): 9966-9969.

[64] PAPPENFUS T M, HENDERSON W A, OWENS B B, et al. Complexes of lithium imide salts with tetraglyme and their polyelectrolyte composite materials. Journal of the Electrochemical Society, 2004, 151(2): A209-A215.

[65] TAMURA T, HACHIDA T, YOSHIDA K, et al. New glyme-cyclic imide lithium salt complexes as thermally stable electrolytes for lithium batteries. Journal of Power Sources, 2010, 195(18): 60956100.

[66] TERADA S, MANDAI T, NOZAWA R, et al. Physicochemical properties of pentaglyme-sodium bis(trifluoromethanesulfonyl) amide solvate ionic liquid. Physical Chemistry Chemical Physics, 2014, 16(23): 11737-11746.

[67] MANDAI T, YOSHIDA K, TSUZUKI S, et al. Effect of ionic size on solvate stability of glyme-based solvate ionic liquids. Journal of Physical Chemistry B, 2015, 119(4): 1523-1534.

[68] YAMADA Y, YAEGASHI M, ABE T, et al. A superconcentrated ether electrolyte for fast-charging Li-ion batteries. Chemical Communications, 2013, 49(95): 11194-11196.

[69] HENDERSON W A, MCKENNA F, KHAN M A, et al. Glymelithium bis(trifluoromethanesulfonyl)imide and glyme-lithium bis (perfluoroethanesulfonyl)imide phase behavior and solvate structures. Chemistry of Materials, 2005, 17(9): 2284-2289.

[70] MCOWEN D W, SEO D M, BORODIN O, et al. Concentrated electrolytes: decrypting electrolyte properties and reassessing $\mathrm{Al}$ corrosion mechanisms. Energy \& Environmental Science, 2013,
7(1): 416-426.

[71] AN S J, LI J, DANIEL C, et al. ChemInform abstract: the state of understanding of the lithium-ion-battery graphite solid electrolyte interphase (SEI) and its relationship to formation cycling. Cheminform, 2016, 105(28): 52-76.

[72] NIE M, ABRAHAM D P, SEO D M, et al. Role of solution structure in solid electrolyte interphase formation on graphite with $\mathrm{LiPF}_{6}$ in propylene carbonate. The Journal of Physical Chemistry C, 2013, 117(48): 25381-25389.

[73] MATSUMOTO K, INOUE K, NAKAHARA K, et al. Suppression of aluminum corrosion by using high concentration LiTFSI electrolyte. Journal of Power Sources, 2013, 231(2): 234-238.

[74] MCOWEN D W, SEO D M, BORODIN O, et al. Concentrated electrolytes: decrypting electrolyte properties and reassessing $\mathrm{Al}$ corrosion mechanisms. Energy \& Environmental Science, 2014, 7(1): 416-426

[75] YOON H, HOWLETT P C, BEST A S, et al. Fast charge/discharge of Li metal batteries using an ionic liquid electrolyte. Journal of the Electrochemical Society, 2013, 160(10): A1629-A1637.

[76] SUO L, BORODIN O, GAO T, et al. "Water-in-salt" electrolyte enables high-voltage aqueous lithium-ion chemistries. Science, 2015, 350(6263): 938-943.

[77] SUO L, BORODIN O, SUN W, et al. Advanced high-voltage aqueous lithium-ion battery enabled by "water-in-salt" electrolyte. Angewandte Chemie International Edition, 2016, 55(25): 7136-7141.

[78] ZHENG J, LOCHALA J A, KWOK A, et al. Research progress towards understanding the unique interfaces between concentrated electrolytes and electrodes for energy storage applications. Advanced Science, 2017, 4: 1700032.

[79] DOI T, SHIMIZU Y, HASHINOKUCHI M, et al. Dilution of highly concentrated $\mathrm{LiBF}_{4} /$ propylene carbonate electrolyte solution with fluoroalkyl ethers for $5-\mathrm{V} \mathrm{LiNi}_{0.5} \mathrm{Mn}_{1.5} \mathrm{O}_{4}$ positive electrodes. Journal of the Electrochemical Society, 2017, 164(1): A6412A6416.

[80] HUANG F, MA G, WEN Z, et al. Enhancing metallic lithium batteries performance by tuning electrolyte solution structure. Journal of Materials Chemistry A, 2017, DOI: 10.1039/C7TA08274F. 